\title{
Los no-lugares de la memoria: Barcelona 1888-1929
}

\author{
María GIL POISA \\ Department of Hispanic Studies \\ Texas A\&M University \\ mariapoisa@neo.tamu.edu
}

Recibido: 26/04/2013

Modificado: $19 / 09 / 2013$

Aceptado: 05/11/2013

\begin{abstract}
Resumen
Los no-lugares y los lugares de la memoria son presencias constantes en la vida de toda ciudad, testimonios de la historia y la identidad del espacio y de sus habitantes. En este trabajo pretendo mostrar cómo los espacios de Montjuic y la Ciutadella, ambos lugares con una fuerte carga simbólica para la ciudad de Barcelona, cuentan con roles fundamentales dentro de la memoria colectiva de los barceloneses, como lugares de dolor e, igualmente, de transición, alivio y reconocimiento.
\end{abstract}

Palabras clave: Barcelona, no-lugares, trauma, memoria.

Title: Non-places of memory: Barcelona 1888-1929

Abstract

Non-places and places of memory are constant presences in the life of every city, witness of the history and the identity of the space and its inhabitants. In this work I want to show how the spaces of Montjuic and the Ciutadella, both of them places with a strong symbolic burden for the city of Barcelona, have a fundamental role for the collective memory of people from Barcelona as spaces for pain and, in the same way, places for transition, relief and appreciation.

Keywords: Barcelona, non-places, trauma, memory.

\section{Índice}

1. Introducción

2. Los dos espacios

2.1. La Ciutadella

2.2. Montjuic

3. Los lugares y la memoria

4. Conclusiones

\section{Introducción}

Todas las ciudades, todos los grupos humanos, atesoran recuerdos, huellas que se adhieren a su memoria en forma de imágenes colectivas que, simbólicamente, quedan unidas a diferentes elementos. Hay dos espacios en la ciudad de Barcelona que, por sucesos históricos y circunstancias sociales, cuentan con una importante carga simbólica de dolor y trauma para los barceloneses: Montjuic y la Ciudatella. 
Debemos partir, como introducción, de que ambos, Montjuic y la Ciutadella, son lugares de emplazamiento estratégico para la ciudad; pensados como fortaleza protectora, son también armas de doble filo: debido a su localización geográfica estratégicamente conveniente, al mismo tiempo defienden, limitan y amenazan Barcelona. Si observamos un mapa antiguo de la ciudad, con las murallas todavía en pie, y sin el Eixample, vemos que la ciudad está limitada al Este por el mar Mediterráneo, al Sur encontramos Montjuic $y$, al norte, la Ciutadella. Contando con que estaba totalmente rodeada por murallas, estos límites naturales suponen un importante elemento definitorio de la ciudad para sus habitantes, confinados en su propio espacio, sin posibilidad de expandirlo ni de avanzar. Ciutadella y Montjuic son así considerados lugares limítrofes, que delimitan al mismo tiempo la ciudad y a su gente.

Como veremos, durante años ambos espacios estuvieron cargados de connotaciones de opresión hacia los ciudadanos. Por ello, recurrentemente se trata de volver a ceder estos espacios a la ciudad, con la intención de integrarlos en su espacio natural para crear de nuevo el vínculo con la gente, para reconstruir la identificación perdida de los barceloneses con estos espacios limítrofes, que representan poderosas huellas en la memoria colectiva de la ciudad.

\section{Los dos espacios}

\subsection{La Ciutadella}

El caso de la Ciutadella es quizá más simple que el de Montjuic, ya que el lugar sí consiguió superar su etapa de transición, de ser un lugar de memoria separado, para pasar a ser parte integrada de la vida diaria de la ciudad.

La Ciutadella fue construida por Felipe V en el siglo XVIII como fortaleza militar para controlar la ciudad tras la Guerra de Sucesión. Durante los primeros momentos de represión, Cataluña había apoyado a los Austrias con la idea de poder alcanzar la independencia si ganaban, pensando en los terrenos catalanes en Francia. Perdieron la guerra, y fueron aislados por el gobierno central, quienes establecen su fuerza en la fortaleza, junto con Montjuic, para ayudar a controlarlos. Para su construcción, se destruye parte de la Ribera, el barrio en el que se ubica, tirando casas, hospitales y conventos; de esta forma no sólo se demuestra al pueblo barcelonés que la ciudad ya está definitivamente bajo el mando central, sino que además se les priva de recursos básicos y se toma su espacio. Al mismo tiempo, cerca de allí, en la zona de la basílica de Santa María del Mar, hay fosas comunes procedentes de la resistencia barcelonesa: se retira a las personas de sus lugares vitales para convertir la zona en un lugar de muerte, un no-cementerio en el que sus muertos no están reconocidos, sino amontonados. Negándole esa primera identidad de 
la Ciutadella en la que el lugar formaba parte de la ciudad y sus habitantes la consideraban como un espacio propio, el gobierno central conseguía darle una nueva identidad a lo que ahora sería una fortaleza, minando así en parte la moral de los ciudadanos. De esta forma el espacio cobra una importancia especial no sólo como un lugar físico, sino también como un lugar en la memoria, ligado a la historia personal y los sentimientos de los barceloneses.

En 1841 se inaugura un periodo de transición para la ciudad en el que comienza la demolición de las murallas de Barcelona, para dar espacio de crecimiento y libertad a la ciudad, hasta entonces reprimida, que sufría las consecuencias de un crecimiento desproporcionadamente rápido. Sin embargo, en el caso de la Ciutadella, aunque empieza a ser destruida, nunca llega a concluirse su derribo y, más tarde, durante el reinado de Isabel II, será reconstruida. Trataron de liberar a la ciudad de un espacio amenazador, pero de nuevo el gobierno de Madrid es el que lo impide, manteniéndola en un punto estratégico de la geografía barcelonesa. Es un problema de memoria histórica, con una gran carga para el pueblo, procedente del sistema opresivo bajo el que se encuentran los ciudadanos de Barcelona. Tiene recuerdos y connotaciones para la gente, y con su parcial destrucción se tratará de borrarlos, y de retirar, al menos parcialmente, algunos aspectos difíciles del lugar en la memoria colectiva. Para el gobierno central también es un arma, ya que durante la Regencia se escoge reconstruirla como forma de aviso al pueblo barcelonés $y$, por extensión, al catalán. Esto mismo se ve reflejado durante la Jamancia, la revuelta catalana contra Espartero en 1843; el gobierno central toma Montjuic y la Ciutadella, y bombardea la ciudad desde allí, de forma que Barcelona acaba rindiéndose.

En 1868 empieza una revolución contra el gobierno de Isabel II, quien es destronada, y comienza de nuevo también la destrucción de la Ciutadella como símbolo de la represión centralista. Sólo algunas partes se conservarán, ya que demoler la fortaleza entera resultaba muy caro, pero se buscará una solución alternativa para remodelar la identidad del espacio en la memoria colectiva, y evitar la carga histórica que los ciudadanos asociaban con ella. De esta forma, Prim consigue los terrenos y empieza una nueva etapa de transición para devolver su espacio al pueblo: compensa a sus propietarios y devuelve su territorio a los barceloneses, tratando de disolver la huella en su memoria borrando la parte de la historia que los atormenta. Como dice Hughes, "Prim knew only two well how hated the Citadle was, how impacted with memories of imprisonment, execution and repression. He would be seen as a liberator, freeing Barcelona from its bersmiched history" (Hughes 1992: 355). Comienzan a construirse el parque y las viviendas, que funcionarán 
en parte como agentes de resignificación de todas las cargas negativas con las que contaba el lugar.

Esta eliminación de la identidad a través de la construcción de historia y la interrupción de la memoria tiene como objetivo que los ciudadanos de Barcelona dejen de asociar este espacio que pertenece a su ciudad como algo negativo, y que lo adopten como un lugar propio. El sentimiento de pertenencia se reconstruirá sobre el terreno, y funcionará como transición entre el no-lugar, con una identidad disuelta para evitar una carga negativa, y un nuevo lugar que se reconstruirá sobre las cenizas del anterior, para crear un nuevo lugar cercano y que la ciudad, otra vez, pueda sentir como suyo un espacio que, además, está ya completamente integrado en la ciudad, y que resulta especialmente conveniente para los barceloneses por su localización. Pero precisamente por esta razón, eso no podrá suceder hasta el momento en que la gente comience a usar el espacio y a entenderlo como algo propio; los lugares que las personas no identifican como algo cercano no están dotados de una identidad, por lo que se convierten, de nuevo, en "no-lugares" (Augé 1993). Al volver a integrar un espacio que resulta problemático en la vida cotidiana de Barcelona, se le da un nuevo significado y se recupera para la ciudad.

Al mismo tiempo, fragmentos de esta identidad recobrada serán adoptados como parte del movimiento catalanista que resurgía. La construcción del parque tomó diferentes influencias francesas e italianas, y sirvió para darle un nuevo estilo e impulso a la ciudad, estimulando su carácter europeo, y separándola así de lo que se consideraba propio de España; cambian y construyen su identidad a través del orgullo nacional y la contraposición con el centralismo castellano, que se consideraba el enemigo. Estos símbolos nacionales que el pueblo asociará con su sentimiento identitario catalán serán destruidos por el Franquismo más tarde, y sustituidos por los símbolos del régimen, en un nuevo intento por modificar la identidad asociada al lugar.

La siguiente gran transformación de la Ciudatella se produce durante la Exposición Universal de 1888. Con un evento internacional de esta magnitud se trató de poner a Barcelona en el mapa internacional, como una entidad separada de la capital española, Madrid, buscando la identificación de la ciudad y su una transformación en una entidad europea, separada, o al menos no exclusiva, de España. El artífice de la exposición fue, inicialmente, el gallego Eugenio Serrano, quien tuvo problemas para llevarla a cabo, entre otras cosas, por no ser originario de Cataluña. La Ciudadela acogió así la parte central de la Exposición, y este acontecimiento funcionó como hito de transición para toda la ciudad, un evento pensado para su transformación en la "nueva Barcelona". La exposición dio un lugar en Europa a Barcelona, y ayudó a impulsarla 
industrialmente, así como a desarrollar el movimiento modernista catalán.

Igualmente, el terreno sigue teniendo un significado concreto para los barceloneses. Por un lado, recuerda una guerra perdida y, por otro, funciona como cementerio de cadáveres anónimos en las fosas comunes. Además, durante mucho tiempo es uno de los símbolos de represión de Castilla, ya que sirvió de elemento de control por los partidarios de los Borbones. El control y la destrucción hacen que el pueblo barcelonés sienta rencor y rechazo hacia la construcción, por encarnar las amenazas del rey en Madrid. El lugar basa su identidad desde su construcción en el vínculo con la casa real, Castilla y Madrid como la oposición, el símbolo de la opresión centralista hacia el pueblo catalán. Además, su localización y su función estratégica proveen al lugar de una importante carga histórica. La historia de la Ciutadella construyó su aureola de lugar de represión en el inconsciente colectivo de Barcelona, que tardó mucho tiempo en liberar de esa carga al espacio que vigila a la ciudad desde las alturas. Cuando esta identidad dolorosa y agresiva se retira y requiere de un nuevo significado, pasa a ser durante un tiempo un no-lugar, un espacio liminal y de transición. A ese no-lugar le seguirá la construcción de una identidad positiva, que lo convierta de nuevo en un lugar antropológico al recuperar una identidad diferente.

\subsection{Montjuic}

El otro espacio comparable a la Ciutadella en la historia de Barcelona es el monte, y el castillo, de Montjuic. El nombre del monte parte de una ya profunda carga sentimental para la historia de Barcelona. Montjuic, el monte judío, cuenta con un importante peso cultural asociado a este grupo tradicionalmente perseguido y expulsado, obligado a la diáspora y la conversión continuas. Desde antes del siglo IX se localizaba a los pies del monte el cementerio judío, alejado del centro de la ciudad, permanentemente rechazado: mientras que los cementerios cristianos tradicionalmente se colocaban en el centro, junto a la iglesia, con fácil acceso y reconocimiento, los judíos enterraban a sus muertos en los límites de la ciudad, a los pies de la montaña. Es este un interesante punto de unión con la historia de la Ciutadella, que también sirvió de lugar de entierro, en este caso en fosas comunes.

En el siglo XVII se construye en el monte un castillo como sistema de protección, que es tomado por los Austrias durante la Guerra de Sucesión, y recuperado por los Borbones tras la victoria. EI antiguo castillo acabará siendo derruido, y sustituido por otro en el siglo XVIII. Este edificio será invadido por los franceses más tarde, durante el principio de la Guerra de la Independencia (1808-1814). El castillo es un punto clave para la ciudad: desde Montjuic, Barcelona ha sido protegida, controlada $\mathrm{y}$, en cierto modo, amenazada. 
Paralelamente a la Ciutadella, empieza a crecer en la memoria colectiva una relación entre Montjuic y el castillo, y la fortaleza al otro lado de la ciudad. Al igual que la Ciutadella, el castillo de Montjuic vigilaba Barcelona desde su rol como emplazamiento del poder centralista y, bajo las órdenes del gobierno de Espartero primero y el de Prim después durante la Jamancia, se les bombardea desde allí. Así el castillo, en lo alto del monte, carga con el papel de ser una amenaza geográfica para los ciudadanos de Barcelona.

Ya en el siglo XIX, el castillo pasa a ser prisión para los representantes de los movimientos obreros reprimidos durante las revueltas anarquistas, así como patio de ejecuciones y sala de tortura. Es especialmente recordado en este periodo por los procesos de Montjuic. Tras un atentado anarquista en 1896, más de ochenta personas son arrestadas y acusadas, sometidas a juicios de guerra y varios de ellos condenados a muerte, mientras que los demás fueron desterrados o mantenidos en prisión. Debido al ambiente de revuelta generalizado en la ciudad, estos procesos y, por tanto, el lugar que los acoge, quedan grabados en la memoria de los ciudadanos como una amenaza dentro de su propio espacio. Además, y unido a todo esto, cabe decir que parte de la historia del monte es la de un cementerio que se encuentra a sus pies. Para cubrir necesidades demográficas e higiénicas de la ciudad, en Montjuic en el siglo XIX se construyó el Cemeteri Nou, mirando en dirección al mar. Se construye en 1883, tratando de suplir una necesidad ciudadana; Barcelona contaba con pequeños cementerios en la ciudad, pero la tendencia a mantener a los muertos en el centro de las ciudades empieza a perderse, y se busca un espacio amplio y periférico donde refugiarlos. Hay que tener en cuenta que en Montjuic se llevaron a cabo juicios y ejecuciones, hubo fosas comunes y lugares para la tortura y, al mismo tiempo, los barceloneses descansaban en la falda de la montaña, a la sombra del castillo.

Para intentar contrarrestar la carga del lugar y tratar de hacerlo más accesible para la gente, en 1929 se empieza a preparar la nueva Exposición Universal, bajo el recuerdo de cómo la exposición de 1888 había permitido remodelar la Ciutadella y, de hecho, toda la ciudad. De nuevo se trata de rehacer la memoria del pueblo, quitar parte del peso de la carga histórica del lugar a los ojos de los barceloneses, y abrirlo sentimentalmente para que se volviese a aceptar la montaña como parte de la urbe. La exposición supone un nuevo avance tecnológico, industrial y urbanístico para la ciudad: se remodela la zona, se mejoran las comunicaciones y, sobre todo, se trata de alejar el pasado para construir un nuevo presente para Barcelona. Años después se sufrirá el mismo proceso, ya que Montjuic vuelve a ser escenario de torturas y ejecuciones durante la Guerra Civil y la dictadura franquista $y$, de nuevo, se intentará despojar al espacio de la memoria negativa para neutralizarlo y, más tarde, darle una nueva 
identidad positiva para sus habitantes. Para ello se localizará allí el evento que, definitivamente, puso a Barcelona en el mapa europeo en el siglo XX: los Juegos Olímpicos de 1992. En la actualidad, todavía se está intentando superar ese periodo, y Montjuic es utilizado para eventos culturales y sociales, tratando de devolverles a sus ciudadanos un espacio que fue legítimamente suyo.

\section{Los lugares y la memoria}

En estas últimas décadas, el francés Pierre Nora desarrolló en 1989 el concepto de los lugares de la memoria en su teoría sobre la historia y la memoria, que se ajusta al proceso que los habitantes de Barcelona siguen al identificar ambos espacios de la Ciutadella y Montjuic con los recuerdos y la identidad interna de la ciudad.

Nora diferencia entre la memoria como la organización involuntaria interna del pasado y la historia como la reconstrucción consciente del pasado por el hombre. De esta forma tenemos que todo el mundo tiene memoria, entendiendo así que todos conservamos recuerdos y los organizamos dentro de ella, creando así nuestra propia realidad y, por lo tanto, nuestra historia interna. La memoria no es absoluta porque depende de la persona, no hay una memoria única que podamos considerar verdadera, pero el recuerdo siempre es real, aunque la realidad sea relativa. No podemos recordar todo tal cual sucede, retenemos cosas sueltas, retazos incluso a veces modificados o inventados; nuestra relación con el pasado siempre es de construcción, nunca de objetividad. La memoria no funciona como la historia, no se basa en datos y hechos aceptados de forma colectiva; cada persona sólo puede almacenar sus propios recuerdos y vivencias, seleccionados $y$, muchas veces, alterados, por lo que cada memoria, cada compilación de recuerdos, es diferente, pero todas son reales: lo que la persona recuerda es real para ella, con lo que se convierte en su realidad, a diferencia de la historia, que será construida a través de la documentación, pero nunca será real para nadie, porque nadie la vivió de esa forma. Igualmente, y atendiendo al autor, la historia es relativa porque depende de quien la escriba, pero tampoco es compartida por todos; la historia es construida seleccionando y organizando datos, y creando de esta forma una realidad que va a ser aceptada por el sujeto, ya que se basa en hechos.

De acuerdo a esto, se puede hacer historia de lo que no se ha vivido, pero no memoria; como la historia la construimos desde datos, archivos, documentos, podemos tratar de reconstruir los hechos. La historia lo que hace es tratar de destruir recuerdos para construir algo nuevo, que no se va a identificar con la realidad y la memoria de nadie, pero tratará de crear una memoria colectiva "real". Se basa en documentación, en hechos, que selecciona y reordena y, según el autor, esto ha acabado destruyendo la memoria: 
"there is no spontaneous memory" (Nora 1989: 12), ya que necesitamos prueba de todo, lo cual no implica verdad. Esta concepción de la historia plantea serios problemas, ya que es imposible recopilar todo el material potencialmente histórico, por lo que una reconstrucción "real" es inviable, y más con los medios con los que contamos ahora, con los que es mucho más fácil acceder a la información pero, al mismo tiempo, también crearla, por lo que el proceso de selección y organización es mucho más complejo y, al mismo tiempo, cuestionable. Atendiendo a esto, podemos decir que se puede hacer historia pero, por un lado, la historia de un historiador diferirá definitivamente de la de otro $y$, al mismo tiempo, de los recuerdos de los que vivieron el momento estudiado. Si trabajamos por ejemplo sobre la bomba del Liceu en 1893, podemos encontrar diferentes historias basadas todas en los mismos datos, dado que todo va a depender de cómo estos datos sean seleccionados y organizados por los distintos historiadores y, al mismo tiempo, hasta hace unas décadas podríamos encontrar gente que recordase el incidente o que, incluso, hubiese estado allí. Así tendríamos diferentes versiones históricas, todas basadas en hechos, y también diferentes visiones y memorias sobre el mismo incidente, todas igualmente válidas: desde la persona que estaba en el Liceu aquella noche, a uno de los anarquistas implicados o alguien que leyó la noticia en un periódico. ¿Cambia eso el hecho? No, pero cada historia nos dará una realidad distinta, y cada memoria será construida por recuerdos de una forma diferente, lo que nos deja con un montón de realidades, todas ellas ciertas $y$, al mismo tiempo, falsas, sobre un mismo hecho: la bomba en el Liceu.

Este mismo hecho podemos analizarlo desde la perspectiva del espacio. Tras el atentado, tenemos en el Liceu un espacio histórico (por razones diferentes de aquellas por las que había sido considerado histórico hasta el momento), un espacio en el que se han dado unos hechos que, por relevantes y documentados, están presentes en cualquier historia de la ciudad de Barcelona. Pero, al mismo tiempo, nos encontramos con un espacio de la memoria, tal y como Nora nos lo plantea, ya que el Liceu representa una serie de recuerdos y elementos simbólicos para los barceloneses, lo que lo carga de unas connotaciones que otros espacios históricos no tienen por qué tener.

Estos lugares de la memoria son definidos por Nora como "moments of history torn away from the movement of history, then returned; no longer quite life, not yet death, like shells on the shore when the sea of living memory has receded" (Nora 1989: 12). Son lugares, hechos, personas,... elementos con significado para la gente, aun no habiendo sido recogidos con ese mismo sentido o valor en la historia oficial. Así tenemos que, mientras que la historia podemos construirla, los lugares de la memoria no son controlables, dependen 
del impacto del pasado en las personas. Un lugar de la memoria puede conservar las connotaciones que un suceso histórico en concreto ha provocado en las personas incluso después de que éste esté olvidado. De esta forma hay personas que no tienen que conocer necesariamente lo sucedido, pero que han "heredado" ese sentir dentro de la memoria colectiva que rodea ese espacio.

Nora dice también que los "lieux de mémoire are created by a play of memory and history, an interaction of two factors that results in their reciprocal overdetermination" (Nora 1989: 19). No son lugares con voluntad de permanecer en la memoria de la gente, es algo inconsciente que marca a las personas de tal manera que su esencia queda impregnada de ese pasado, y adquieren un carácter simbólico, se convierten en huellas que tardan mucho en borrarse, y necesitan perder esas connotaciones para poder construirse una nueva identidad y superar la etapa de dolor. Estos lugares acaban perteneciendo únicamente a la memoria; incluso cuando el espacio o elemento afectado por el recuerdo desaparece, el dolor sigue ahí, y la gente necesita perder estas connotaciones. Son lugares que corresponden a la memoria, que no pueden existir fuera de ella y que, aunque el espacio pierda su sentido, serán recordados, quizá como algo distinto, pero perdurarán en la memoria de la gente, con la sombra del pasado flotando siempre sobre el presente.

El ser humano tiene una necesidad inconsciente de recordar: "Memory attaches itself to sites, whereas history attaches itself to events" (Nora 1989: 22). Un lugar de la memoria es recordado por la gente porque tiene interés; un lugar histórico lo es porque el sistema lo ha decidido así. Los lugares de sucesos, de recuerdos, son personales y sociales, no históricos, no son controlables. Su situación y circunstancias son accidentales, no planeados. Podemos poner una estatua a alguien en cualquier sitio y que siga siendo una pieza de historia, un homenaje que decidimos dónde colocar; sin embargo, un lugar de la memoria no puede colocarse aleatoriamente, ya que está ligado a un espacio, y no puede ser controlado. No podríamos cambiar de sitio Montjuic, o la Ciutadella, precisamente porque lo importante no son únicamente el castillo ni la fortaleza, sino el espacio donde se encuentran, por los sucesos que allí tuvieron lugar y que fueron retenidos en la memoria colectiva de Barcelona. Estos lugares, como dice Nora, "have no referent in reality; or, rather, they are their own referent" (Nora 1989: 23), y serán recordados por todos, pero para cada uno sugerirá un recuerdo que puede ser totalmente distinto. Los juicios de Montjuic no eran recordados de la misma manera por los familiares de los anarquistas que por los que los condenaron. Todos estos símbolos carecen de un valor propiamente objetivo, son totalmente subjetivos, por lo que la única forma de medir su importancia es a través de las huellas que dejan en la memoria de las personas. 
Así, y pensando en las historias de los lugares que nos atañen, podemos considerar que ambos son lugares de la memoria, por todos los sentimientos y recuerdos que tienen asociados para los barceloneses, incluso para aquellos que no conocen su historia. De esta forma, el duelo de Montjuic no se ha superado todavía, porque la gente aún lo recuerda como un lugar con una fuerte carga emocional, ya que los sucesos que lo provocan están demasiado recientes en el tiempo, y los recuerdos que se le asocian todavía cargan con una historia que no está superada, no ha conseguido un nuevo significado en la memoria colectiva de Barcelona. La Ciudatella, sin embargo, sí ha podido recuperarse del momento de aflicción, ya que ese sentimiento fue negociado y su duelo superado a través de la destrucción y reconstrucción del lugar. Ambos son lugares de la memoria: son espacios materiales, simbólicos para la gente, y con una función social asignada, que no siempre se corresponde con la que las personas le acaban dando. Aunque Montjuic quiera utilizarse ahora como espacio público y social para los barceloneses, va a necesitar un tiempo para superar el momento de transición en el que este lugar de la memoria pierda esa parte de su identidad para convertirse en un lugar neutro, un no-lugar, que más tarde vuelva a ser un espacio perteneciente a todos los ciudadanos, y que ellos dejen de asociar con los recuerdos que lo acompañan ahora.

Todos estos espacios con memoria cumplen una función necesaria, y en muchas ocasiones pueden ser clasificados dentro de una de las dos categorías que Foucault diferencia en su conferencia "Los espacios otros": utopías y heterotopías, siendo estas últimas los que nos interesan para este trabajo. El filósofo francés dijo que "las utopías son los lugares sin espacio real. [...] Se trata de la misma sociedad en su perfección máxima o la negación de la sociedad, pero, de todas suertes, utopías con espacios que son fundamental y esencialmente irreales" (Foucault 1984). Esta perfección es conscientemente irreal $y$, con ello en mente, el autor dibuja la heterotopía como contraste a la utopía; espacios reales que la sociedad construye como espacios de "otredad", espacios que podemos localizar y definir pero que, sin embargo, se oponen al resto de ellos, "son completamente distintos de todos los espacios de los que son reflejo y alusión" (Foucault 1984). Se definen por contraste con el resto de los espacios, reales pero imperfectos. En su teoría de las heterotopías, Foucault habla de las heterotopías de crisis como lugares "aforados, o sagrados o vedados" (Foucault 1984): son lugares de protección o iniciación, de transición vital, pero sin referencias que los individualicen o los hagan relevantes, que los diferencien entre ellos. En contraste a estas, Foucault define las heterotopías de desviación, pensadas para aislar al elemento que no sigue el camino que la sociedad le impone. De acuerdo a esto tenemos que, mientras unas de ellas unen durante los momentos de 
crisis, las otras tratan de apartar el problema, ya no sirven para integrar, sino para desintegrar, y es el uso que se les dé a estos lugares y la aceptación social que tengan lo que los convertirá, con el tiempo, en un tipo de espacio o en otro.

Pero de la misma forma existe una versión feliz de estas heterotopías, una yuxtaposición de espacios en un solo lugar físico, lo que Foucault ejemplariza mediante la figura de los jardines como contenedores de todo el universo. Esta es la siguiente etapa de transición para la Ciutadella y Montjuic, pasar del espacio desviado al espacio de felicidad y perfección real creada por una sociedad que necesita construir unos nuevos recuerdos y darle otro significado al lugar. Cuando se pasa por ese periodo de anulación de la identidad corrupta, que el pueblo siente como opresión, se transforma el espacio heterotópico, y éste se convierte en un lugar de transición pensado para reflejar una perfección real, localizable y que, al mismo tiempo, no representa la realidad, sino que crea una nueva identidad al lugar que lo desvincula de su pasado y modifica la memoria histórica, para adaptarla a los ciudadanos. En ese mismo sentido, cuando Montjuic y la Ciudatella albergan las exposiciones universales, están siendo convertidos en espacios heterotópicos de perfección, que al mismo tiempo pueden responder al concepto de simulación baudrillardiano.

En su concepto de simulacro hiperreal, Baudrillard (2002) expone el ejemplo de Disneyland, el espacio perfecto que simula la realidad pero que no es real, sino una farsa: al visitarlo, el ciudadano entra en un mundo de cuya falsedad es perfectamente consciente, pero no le importa, dado que la existencia de ese espacio se basa en su propia irrealidad: como sabe que nada es real, todo lo que se represente va a serlo. En estos espacios la ilusión de la realidad se hace más evidente: si todos ellos son falsos pero parecen reales, ¿por qué van a ser reales los demás? Mediante las exposiciones, los distintos pabellones trataban de exponer una realidad con la que identificar sus territorios, exhibían su identidad a través de un evento cultural y social en el que esa supuesta realidad estaba representada pero, al mismo tiempo, era completamente inventada. En este tipo de exposiciones cada pabellón refleja, simula, no la realidad de los territorios, sino sus aspiraciones, su interés por cómo ser percibidos a los ojos de otros. De esta forma, los espacios que sirven en este caso para representar identidades ajenas están, al mismo tiempo, afianzando la identidad local. Las exposiciones pusieron a Barcelona en el mapa del mundo occidental, a través de los propios intereses de los integrantes de ese mundo, pero al mismo tiempo tuvieron una función interna fundamental dentro de la ciudad: el darle un nuevo significado a estos lugares que, por su localización y su historia, necesitaban ser reubicados en la percepción colectiva de los ciudadanos. 


\section{Conclusiones}

Al utilizar como escenario para estos eventos dos lugares de la memoria con una fuerte carga histórica para los barceloneses, lo que la ciudad estaba haciendo era comenzar a liberar esos espacios. Lo que se trataba de hacer era reasignar un significado a esos lugares con una fuerte carga sentimental en el imaginario colectivo. Abandonaban así su historia de opresión, ejecuciones y destrucción en la memoria del pueblo, ganando una connotación positiva a sus ojos, aliviando su carga y recobrando un sentimiento de aceptación pero sin pasar por el olvido. Para hacerlo se necesitaba un momento de transición, durante el cual el espacio sería transformado. Lo que, siguiendo la concepción de Augé, era un lugar antropológico con todas sus características, espacios con identidad, relación e historia, debería convertirse sin embargo en todo lo contrario, en un no-lugar, para conseguir esta transición y despojarse del dolor que la gente asocia con él. Augé entiende el no-lugar como "espacio que no puede definirse ni como espacio de identidad ni como relacional ni como histórico" (Augé 1993: 83), y es precisamente esto lo que la ciudad de Barcelona intenta hacer con estos espacios al devolvérselos a los barceloneses en forma de bellos parques y fastuosas exposiciones. Si consiguieran que la gente dejase de ver estos lugares en parte como cementerios y patíbulos, les estarían haciendo perder su funesta memoria para sustituirla por una nueva identidad aséptica y neutra, el no-lugar, que podría dar paso a un nuevo lugar de la memoria, asociado en este caso con valores positivos: la Nueva Barcelona.

En esta Barcelona inmensa, heredera de su historia, lugares como la Ciutadella y Montjuic fueron espacios políticos para la gente, espacios que construyeron su memoria a través de una concepción centralista y militar que les fue impuesta, que derivó en una serie de terribles recuerdos para los ciudadanos asociados con muerte, represión y tortura. Los mismos espacios que estaban pensados y perfectamente situados para la protección de la ciudad, para hacer que sus ciudadanos estuviesen cómodos y creasen un sentimiento de arraigamiento y pertenencia a Barcelona, fueron convertidos en espacios políticos y de amenaza; los espacios ya no eran naturales, habían sido manipulados por el hombre, a través de acciones políticas y militares, para modificar su percepción por la gente $y$, de esta forma, corromper la atmósfera social de la ciudad: la transformación del espacio para la transformación de la población. La forma que los propios dirigentes de la ciudad encuentran para deshacer esta situación y devolver a los barceloneses los espacios que por derecho les pertenecían es deshaciendo estos recuerdos, estos espacios de la memoria, despojándoles de su identidad histórica asociada a las desgracias y convirtiéndolos temporalmente en no-lugares que ayudasen a la gente a olvidar, para transitar del lugar cargado de 
recuerdos al lugar aceptado y reconocido que los barceloneses desean para su ciudad.

\section{Bibliografía}

AUGÉ, Marc (1993): Los "no lugares". Espacios del anonimato. Una antropología de la sobremodernidad. Barcelona: Gedisa.

BAUDRILLARD, Jean (2002): Cultura y simulacro. Barcelona: Kairós.

ESPUCHE, A. G.; GUARDIA, M. et al. (1991): "Modernization and urban beautification: The 1888 Barcelona world's fair". Planning Perspectives, vol.6, núm. 2, pp. 139-159.

FOUCAULT, Michel (1967): "Des espaces autres" [en línea], Conferencia dictada en el Cercle des Études Architecturals, 14 de marzo de 1967. En: http://textosenlinea.blogspot.com/2008/05/michel-foucault-losespacios-otros.html [Consultado: 05/12/2012].

FREUD, Sigmund (1917): "Duelo y melancolía", en Obras Completas, tomo XIV. Buenos Aires: Amorrortu Editores.

GARCÍA MÁRQUEZ, Gabriel (1976): Cien años de soledad. Buenos Aires: Editorial Sudamericana.

HUGHES, Robert (1992): Barcelona. New York: Knopf.

KORSTANJE, Maxi (2006): "El viaje: una crítica al concepto de no-lugares". Atenea Digital, vol. 10, otoño 2006, pp. 211-238.

MARTÍN-BARBERO, Jesús (2006): "Pensar juntos espacios y territorios", en Diego Herrera Gómez y Carlo Emilio Piazzini Suárez (eds.), (Des)territorialidades y (No)lugares: Procesos de configuración y transformación social del espacio. Medellín: Universidad de Antioquia.

MORAN, Joe (2005): Reading the Everyday. London / New York: Routledge. NOGUÉ, Joan; y VICENTE, Joan (2004): "Landscape and national identity in Catalonia". Political Geography, vol. 23, pp. 113-132.

NORA, Pierre (1989): "Between Memory and History: Les Lieux de Mémoire". Representations, vol. 26, Spring, pp. 7-24.

PUJADAS, Xavier (2012): "Sport, Space and the Social Construction of the Modern City: The Urban Impact of Sports Involvement in Barcelona (1870-1923)" [en línea]. The International Journal of the History of Sport, vol. 29, núm. 14. En: http://www.tandfonline.com.libezproxy.tamu.edu:2048/doi/full/10.1080/09523367.2012.696348\#.U jpTycajSz0 [Consulta: 18/09/2013].

RIVERA, David (2011): "La arquitectura del no-lugar y la odisea contemporánea". DC Papers. Revista de crítica y teoría de la arquitectura, núm. 21-22, diciembre 2011, pp. 35-44.

SORKIN, M. (ed.) (2004): Variaciones sobre un parque temático. Barcelona: Gustavo Gili.

VÁSQUEZ ROCCA, Adolfo (2007): "El vértigo de la sobremodernidad: 'no lugares', espacios públicos y figuras del anonimato". Nómadas, vol. 016, pp. 197-203. 